\title{
A RELAÇÃO ENTRE EDUCAÇÃO E DESENVOLVIMENTO ECONÔMICO NO CAPITALISMO: ELEMENTOS PARA UM DEBATE
}

\author{
Neide de Almeida Lança Galvão Favaro ${ }^{1}$ \\ Paulo Sergio Tumolo ${ }^{2}$
}

\begin{abstract}
RESUMO: $\mathrm{O}$ artigo analisa a relação entre educação e desenvolvimento econômico tal como aparece na produçáo teórica mais recente de Dermeval Saviani, autor matricial da pedagogia histórico-crítica. Sua proposta é a de converter o investimento em educação no eixo principal do desenvolvimento, superando a falta de "vontade política", o que beneficiaria toda a sociedade em todos os campos econômico-sociais. Paralelamente, a necessidade de "publicização do Estado" é reivindicada. O autor argumenta que sua proposta é concernente com a luta socialista, pois sua realização implicaria um processo de socialização dos meios de produção, já que, para ele, o conhecimento é um meio de produção. Essas proposiçóes e suas consequências políticas para a luta de classes são aqui questionadas.
\end{abstract}

Palavras-chave: Educação. Desenvolvimento econômico. Capitalismo.

\section{THE RELATION BETWEEN EDUCATION AND ECONOMIC DEVELOPMENT IN THE CAPITALISM: ELEMENTS FOR A DEBATE}

ABSTRACT: The article analyzes the relation between education and economic development as it appears in the most recent theoretical production of Dermeval Saviani, main author of the historical-critical pedagogy. His proposal is to convert the investment in education in the main axis of the development, overcoming the lack of "political will", which would benefit the whole society in all social-economic fields. In parallel, the necessity of a "State's publicization" is claimed. The author argues that his proposal is related to the socialist fight, as its fulfillment would imply a socialization process of the means of production, since that, to him, knowledge is a mean of production. These propositions and their political consequences to the class struggle are questioned here.

Keywords: Education. Economic development. Capitalism.

\footnotetext{
${ }^{1}$ Universidade Estadual do Paraná - Paranavaí (PR), Brasil. E-mail: neidegafa@hotmail.com ${ }^{2}$ Universidade Federal de Santa Catarina - Florianópolis (SC), Brasil. E-mail: paulo.tumolo@ufsc.br DOI: 10.1590/ES0101-73302016149345
} 


\section{LE RAPPORT ENTRE L'ÉDUCATION ET LE DÉVELOPPEMENT ÉCONOMIQUE DANS LE CAPITALISME: LES ÉLÉMENTS D'UN DÉBAT}

RESUMÉ: Cet article présente le rapport entre l'éducation et le développement économique tel qu'il apparaît sur la production théorique de Demerval Saviani, l'auteur principal de la Pédagogie HistoricoCritique. Sa proposition est convertir l'investissement dans l'éducation en l'axe principal du développement, en surmontant le manque de «volonté politique», ce qui serait bénéfice à l'ensemble de la société dans tous les domaines sociaux-économiques. En même temps, la nécessité de faire connaître l'État est revendiquée. L'auteur fait voir que sa proposition vise la lutte socialiste, parce que sa mise en oeuvre impliquerait un processus de socialisation des moyens de production, puisque pour lui la connaissance est un moyen de production. Ces propositions et leurs conséquences politiques pour la lutte de classe sont ici mises en question.

Mots-clés: Éducation. Développement économique. Capitalisme.

\section{Introdução}

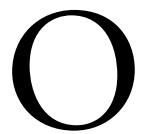

debate educacional brasileiro no campo da esquerda ganhou um impulso considerável no período final da ditadura militar-burguesa, entre o final da década de 1970 e o início da década de 1980. Dentre os diversos autores que se lançaram à tarefa de analisar criticamente a educação existente, destaca-se Dermeval Saviani. Ele foi responsável por agregar um grupo de educadores no Programa de Pós-graduaçáo em Filosofia da Educaçáo da Pontifícia Universidade Católica (PUC), de São Paulo, cuja proposta era analisar a educação escolar em suas contradições e formular uma teoria educacional que contribuísse para a tarefa de implantação de novas relaçôes sociais.

Assim foi elaborada coletivamente a pedagogia histórico-crítica, cujo autor matricial é Saviani, que se dedicou a superar as teorias pedagógicas de caráter liberal, denominadas inicialmente de "não críticas", bem como algumas teorias educacionais que considerava "crítico-reprodutivistas". Por meio de uma intensa produção teórica elaborada nos últimos 30 anos, Saviani apresentou proposições de intervenção prática nas políticas educacionais brasileiras. Nos limites deste artigo, analisaremos suas propostas vinculadas à relaçáo entre educaçáo e desenvolvimento econômico, além de problematizar suas consequências políticas para a luta de classes.

A compreensão de suas formulaçôes teóricas exigiu a investigação dos distintos momentos de sua elaboração, que foram divididos em dois períodos: as décadas de 1970 e de 1980, marcadas pelo contexto de reestruturação do capital e 
por um ascenso nas lutas da classe trabalhadora, que não serão aqui exploradas em virtude dos limites deste artigo; e o período que abrange a década de 1990 até os dias atuais, em que se intensificaram as transformaçóes produtivas, acompanhadas de um refluxo do movimento de contestação operária, gerando posicionamentos mais contundentes de Saviani em relação à questáo aqui investigada.

Embora a articulação entre educação e desenvolvimento brasileiro permeasse parte da produção teórica de Saviani na primeira fase, em que discutiu a necessidade de superação do "subdesenvolvimento" e de "humanização" do desenvolvimento nacional com o auxílio da educação, a análise do período posterior à década de 1990 permite identificar o seu posicionamento político-estratégico mais recente, após experiências concretas de implantação da pedagogia histórico-crítica.

\section{A educação como "eixo do desenvolvimento econômico" na produção recente do autor}

Em meados dos anos de 1978 a 1984, a luta pela democracia marcou profundamente o autor, o que é constatável pelo próprio título atribuído à obra basilar da pedagogia histórico-crítica: Escola e democracia (SAVIANI, 2003). Essa estratégia estava em consonância com as demais reivindicaçôes sociais, pois esse período foi marcado pela política de "abertura", em que os setores da oposição ampliaram seu espaço político, enfrentando e questionando a legitimidade do governo ditatorial.

O período que compreende a década de 1990 até a atualidade trouxe alteraçôes significativas ao conjunto das relaçôes sociais de produção e, consequentemente, à dinâmica da luta de classes. Se o final dos anos de 1970 e o decorrer da década seguinte foram marcados por um influxo do movimento de contestação operária no Brasil, os últimos 20 anos foram responsáveis por assegurar a contenção dessas lutas, recolocadas em parâmetros aceitáveis para assegurar o processo de acumulação do capital. No campo educacional, Saviani propôs a "estratégia de resistência ativa", que implicava a crítica às políticas educacionais vigentes, mas também a proposição de alternativas consoantes aos interesses populares.

Na primeira metade da década de 1990, a ausência de um sistema educacional unificado foi apontada como uma das causas das dificuldades encontradas nos anos de 1980 para a implantação prática da pedagogia histórico-crítica nas redes de ensino; além de ser considerada também um impedimento para o próprio desenvolvimento brasileiro.

Nessa mesma época, após uma análise histórica das relaçóes entre educação e trabalho, Saviani (1994, p. 160) apontou o cerne da contradição escolar no âmbito do capital, que impedia o avanço dos sistemas de ensino. Para o autor, o saber era necessário aos trabalhadores, mas não podia ser ofertado de modo 
integral, já que concebia o saber como meio de produção e/ou força produtiva, e, portanto, na "medida em que o saber se generaliza e é apropriado por todos, entáo os trabalhadores passam a ser proprietários dos meios de produção".

O controle do acesso ao saber era essencial, pois no capitalismo "o trabalhador não pode ter meio de produção, não pode deter o saber" (SAVIANI, 1994, p. 161). Acreditando que a reestruturação produtiva então em curso exigia e já apontava a tendência para a universalizaçáo de uma escola unitária que promovesse o desenvolvimento omnilateral dos indivíduos, Saviani (1994, p. 166) inferia que a implantação do sistema nacional de ensino enfrentava "resistências acirradas, oriundas dos setores conservadores vinculados ao atual governo federal", mas que essa luta já estava sensibilizando até aquela "área mais recalcitrante da 'Intelligentia' nacional representada pelo empresariado". Preconizou então que, "sem um sistema educacional consolidado sobre a base de uma escola elementar comum universalizada, não será possível modernizar o parque produtivo nacional", inviabilizando nossa modernização tecnológica, o aumento da produtividade e nosso ingresso no "Primeiro Mundo". A preocupação com relação ao desenvolvimento do país e das empresas capitalistas subentendia aí a ampliação do próprio capitalismo.

Também foi na década de 1990, ao apresentar uma proposição alternativa para o Plano Nacional de Educação (PNE), que Saviani (2002) propôs a luta por outra política educacional, que superasse a lógica de mercado, raiz das dificuldades existentes. $\mathrm{O}$ objetivo era promover a democratização e adotar a "racionalidade social", sendo que o ponto básico para romper este círculo vicioso era o dos investimentos. Era necessário um projeto de desenvolvimento centrado no homem, não no mercado.

Mesmo reconhecendo a determinação estrutural que sob o capital subordina as políticas sociais às econômicas, concebia a necessidade da luta pela valorizaçáo das primeiras, visto que assim estar-se-ia "tentando utilizar o Estado como instrumento de neutralização do processo de apropriação privada dos bens socialmente produzidos", apontando no sentido da "socialização da economia" e assim, no limite, na "superação do capitalismo" (SAVIANI, 2002, p. 122). Os objetivos da luta, portanto, deveriam ser o equilíbrio entre os recursos da área social e econômica, a oposição às privatizaçôes, bem como o desatrelamento da política social em relação à economia.

Essa proposta foi constante na produçáo do autor. Os rumos da economia brasileira, por sua vez, foram frequentemente associados a uma questão de "prioridade política", sendo necessária a lógica da "racionalidade social" no momento em que as contradiçóes apontavam para a superação da racionalidade financeira, com um projeto de desenvolvimento centrado no homem, não no mercado. Em consonância com tais concepçóes, o autor denunciou o atraso de nossa educação. Ao analisar o legado educacional do século XX no Brasil, Saviani (2004, p. 51) indicou que, na Europa, a implantação dos sistemas nacionais de ensino ocorrera no decorrer do século XIX, mas o "Brasil foi retardando essa 
iniciativa e, com isso, foi acumulando um déficit histórico em contraste com os países que instalaram os respectivos sistemas nacionais de ensino".

A seu ver, os países líderes econômica, política, social e culturalmente seguiram esse caminho, embora reconhecesse que os Estados Unidos eram uma exceção. Este país havia deixado a educação a cargo de órgãos municipais, não havia nem Ministério da Educação e nem uma lei nacional de ensino. O problema era que esse modelo era desigual e apresentava distorçôes, e, por isso, a opção do autor pelo modelo dos sistemas de ensino europeus. Para Saviani (2004, p. 53), o modelo europeu assegurara a homogeneização do "acesso à cultura letrada, o que significou um razoável grau de igualdade de condições de participação de todos na vida social".

O legado negativo do século XX brasileiro não se resolvera e os problemas persistiriam "enquanto as forças dominantes se negarem a pôr em prática as medidas que a experiência já chancelou como sendo as apropriadas para as questóes que estamos enfrentando" (SAVIANI, 2004, p. 54). A relação que estabelecia entre a educação e o desenvolvimento econômico do país reforçava a necessidade de "vontade política" para implantar um sistema nacional de ensino.

Em 2005, Saviani (2010a, p. 227) constatava que o "governo de esquerda", do PT, infelizmente, "se rendeu à ordem instalada e nada está fazendo de efetivo para alterar o estado de coisas vigente". Para o autor, o que ocorria desde a década de 1960 era a adoção de um planejamento educacional que levava em conta a racionalidade técnica, a partir do período militar, marcado pelo tecnicismo; e a racionalidade financeira, a partir de 1990, matizada pelo neoliberalismo.

O período de 1961 até os dias atuais, portanto, fora caracterizado pela hegemonia da concepção produtivista em educação, porque prevalecera a visão formulada na década de 1950 pela teoria do capital humano, segundo a qual a educação era concebida como um bem de produção, um investimento, um agente de desenvolvimento. Essa ideia estaria presente ainda hoje: "como se costuma dizer agora, na sociedade do conhecimento a educação é o diferencial. O grau de educação é que faz a diferença; não é você ter coisas, não é o capital físico" (SAVIANI, 2010a, p. 224 e 225). A distinção entre essa posição e sua defesa da educaçáo como condiçấo do desenvolvimento brasileiro não foi esclarecida. Ao que tudo indica, a mesma estava ligada à forma desse desenvolvimento: humanizado ou a serviço do capital. Essa mudança dependia da luta por uma nova política.

Ao discutir as concepções pedagógicas na história da educação brasileira, Saviani (2006) introduziu uma distinção entre a teoria do capital humano da década de 1950 e a atual, que teria sido alterada desde a crise de 1970. Agora náo era mais o Estado que assegurava nas escolas a preparação da força de trabalho para atender ao mercado, que naquela época "se expandia em direção ao pleno emprego". O indivíduo é que teria de adquirir os meios para se tornar competitivo no mercado de trabalho, para conquistar o status de empregabilidade, embora sem garantias 
de acesso ao emprego, pois a economia capitalista "pode crescer convivendo com altas taxas de desemprego e com grandes contingentes populacionais excluídos do processo. É o crescimento excludente em lugar do desenvolvimento inclusivo que se buscava atingir no período keynesiano" (SAVIANI, 2006, p. 21-22).

Numa entrevista concedida em 2005, quando situou o país em relação à economia mundial, argumentou a favor de sua proposta do PNE, que incluía o aumento dos investimentos do produto interno bruto (PIB) em educaçáo para 8\%. Saviani (2010a) explicou que ela não resolveria todos os problemas da educação brasileira, mas era um pressuposto para iniciar as soluçôes. Diante das objeçóes quanto à viabilidade dessa meta, justificadas pelos escassos recursos do país e por suas imensas carências, ele contestou essas posiçôes destacando sua impaciência com as resistências e defendendo a existência de condiçóes objetivas para a efetivaçáo de sua proposta. $\mathrm{O}$ autor ressaltou que o Brasil estava entre as maiores economias do mundo e, por isso, não era pobre, e sim "injusto".

Diante dessa constatação, a relação entre a educação e o desenvolvimento foi reafirmada e adquiriu maior intensidade. A opçáo estratégica se direcionava para a luta pela priorização da educação na questão dos investimentos, o que exigiu assumir o discurso dominante, cobrando-lhe coerência. A proposta é clara: definir, a partir das bases econômicas do país, o fator estratégico que mobilizaria todas as energias da naçẫo. Isso porque Saviani (2010a, p. 245, grifos nossos) estava "convencido de que o problema todo se resume na questáo da estratégia de desenvolvimento do país".

Ele adotou como pressuposto a existência de um "consenso", inclusive no discurso de empresários e políticos: "de que vivemos na sociedade do conhecimento; de que nesse tipo de sociedade a educação formal é a chave sem a qual todas as portas tendem a ser fechadas", pois sem isso "os indivíduos ficam excluídos" e as empresas perdem produtividade. Sua posição política foi no sentido de assumirmos esse consenso, o que implicava na eleição da educação como fator estratégico de desenvolvimento do país. Isso levou Saviani (2010a, p. 245, grifos nossos) a reformular sua proposta anterior: "Em lugar de apenas duplicar imediatamente o percentual do PIB investido em educação, proponho que carreemos para a educação todos os recursos disponiveis".

Isso não prejudicaria outras áreas, "como saúde, segurança, estradas, desemprego, pobreza etc. Ao contrário, a educação será a via escolhida para atacar de frente, e simultaneamente, todos esses problemas" (SAVIANI, 2010a, p. 245). Ele explicou como isso se daria: ampliando o número de escolas, absorvendo todos os estudantes e contratando os profissionais necessários, bem remunerados. Assim, milhares de empregos seriam criados, muitos alunos seriam retirados das ruas e do assédio do tráfico de drogas, além de promover o desenvolvimento econômico, já que haveria mais consumo, ativando o comércio e a indústria, criando mais empregos. Além de melhorar a qualidade do ensino, "incluiria" os indivíduos na sociedade, melhoraria a "competitividade" das empresas e garantiria mais recursos 
ao Estado, que poderia sanar as principais dificuldades do país. Saviani (2010a, p. 246) enfatizou o impacto social dessa medida, que permitiria ao Estado "arcar com os programas sociais destinados aos agora reduzidos grupos de náo incluídos nesse amplo processo de desenvolvimento geral do país".

Ao concluir a entrevista, lançou uma provocação aos formadores de opinião, políticos e aos empresários, exigindo coerência entre seus discursos e a prática vigente: "Ou assumimos essa proposta, ou devemos deixar cair a máscara e pararmos de pronunciar discursos grandiloquentes sobre educação, em flagrante contradição com uma prática que nega cinicamente os discursos proferidos" (SAVIANI, 2010a, p. 246).

Essa argumentação tornar-se-ia recorrente nos anos posteriores, com poucas modificaçóes, que incorporaram outros elementos. Em entrevista de 2007, por exemplo, ele reafirmou a necessidade da estratégia de resistência ativa. Ao tratar da estratégia de luta para os sindicatos docentes, Saviani (2011) preconizou que ela deveria se apoiar no discurso político e empresarial, que colocava a educação como prioridade número um, reiterando a argumentaçáo exposta anteriormente.

Também em 2007, a estratégia da resistência ativa foi articulada à adoção do discurso dominante. Ao analisar o percurso que foi da Lei de Diretrizes e Bases da Educação Nacional (LDB) ao Fundo de Manutenção e Desenvolvimento da Educação Básica (Fundeb), Saviani (2008a, p. 322) asseverou que não se garantira os recursos necessários para que a educação atingisse um "patamar civilizado". Como considerava que o aumento de recursos para a educação era plenamente viável, ele estava "convencido de que o problema todo se resume na questáo da estratégia de desenvolvimento do país".

Retomando as posiçóes mais recentes, propôs que se assumisse o discurso dominante, destinando todos os recursos à educação, resolvendo assim os demais problemas. Ele indicou uma ironia "na forma" de enunciar a questão, mas não em seu conteúdo, que foi considerado radical e coerente. Desafiava assim que se assumisse o discurso na prática política ou se deixasse "cair a máscara". Saviani (2008a, p. 324) deixava claro que não considerava tal proposta ingênua nem romântica, pois ela extraía com radicalidade as consequências do discurso dominante. "Se há uma pitada de ironia na forma em que foi enunciada, ela foi motivada pelo desejo de cobrar coerência aos portadores desse discurso".

Em 2008 essa mesma estratégia reapareceu, na análise do Plano de Desenvolvimento da Educação (PDE). Saviani (2011) já sinalizava para a dificuldade que haveria para o cumprimento das metas previstas, pois as açóes eram dispersas e não via "vontade política" de priorizar a educação. O principal desafio que identificava era no financiamento, e, por isso defendia o ajuste das decisóes políticas ao discurso imperante, elegendo a educação como máxima prioridade, como eixo de um projeto de desenvolvimento nacional. Radicalizando o discurso dominante, cobrava-lhes coerência. 
Em 2008 foi publicada na revista Educação uma entrevista do autor, intitulada Motor do desenvolvimento. Segundo a matéria, seria esse o papel que Saviani (2008b) defenderia para a educação brasileira: ser a força motriz da economia. Como os investimentos não eram realizados, a qualidade da educação era prejudicada, restando apenas discursos. A solução passava pela definição da educação como eixo do projeto de desenvolvimento nacional, para que a partir dela fossem beneficiados os outros setores. $\mathrm{Na}$ análise do autor, isso fora feito com o automóvel no início do século XX, o que dinamizara a economia dos países capitalistas, apesar dos efeitos colaterais negativos.

Essa mesma posição foi formulada em entrevistas posteriores, de 2009 e 2010, com alguns elementos novos. Ao apontar que a coerência em relação ao discurso dominante implicava colocar a educaçáo como eixo do desenvolvimento econômico, Saviani (2011, p. 211) afirmava ser esse o caminho para criar "o tão desejado círculo virtuoso do desenvolvimento". A partir dela se atacariam e se resolveriam todos os demais problemas, mas isso implicaria uma alteraçáo fundamental: substituir o eixo do desenvolvimento econômico do automóvel, que trouxera efeitos colaterais negativos, como verticalização das cidades, congestionamento do tráfego, poluição, etc.; para a educação, que permitiria "um desenvolvimento com maior distribuição da renda e estimulador da igualdade social", além de trazer "o antídoto aos efeitos negativos", que estaria assegurado na educação ambiental, para o trânsito, etc. (SAVIANI, 2011, p. 212, grifos nossos).

Como está evidenciado, a partir de um "consenso" sobre a importância da educação para o desenvolvimento, Saviani extraiu implicações econômicas profundas decorrentes do investimento na educação. Preconizou que, tornando-se o eixo da economia, ela permitiria superar os problemas sociais em geral, como a desigualdade, os problemas ambientais e infraestruturais.

Como sua estratégica política exige o investimento público em educação, um grande obstáculo passou a ser o neoliberalismo. $\mathrm{O}$ combate às políticas neoliberais assumiu uma posição fundamental no âmbito da produção teórica atual do autor. Além disso, Saviani (1989, p. 6) reivindica a necessidade de "publicizar" o Estado, que consistiria em "encaminhar a ação do Estado para as iniciativas que dizem respeito ao interesse público". Atualmente propõe "republicanizar" a educação, pois assim "estaremos radicalizando uma das promessas da burguesia liberal e, com isso, explorando seu caráter contraditório tendo em vista a superação dessa forma social" (SAVIANI, 2010b, p. 41).

Nesse texto não foi explicitada qual a contradição e nem como ocorreria a superação, mas, considerando o conjunto das obras de Saviani, fica implícita aí a tese do saber como meio de produção, pois garantindo o acesso de todos à educação, as próprias bases produtivas capitalistas seriam derrubadas. O objetivo era superar o capitalismo, com a utilizaçáo do Estado a favor das políticas sociais, levando à socialização da economia. 


\section{Desenvolvimento econômico e educação: algumas questões}

A relação entre educação e desenvolvimento esteve presente na produção teórica de Saviani desde seus primórdios até o período atual. Destacando os elementos centrais, o fio condutor de sua argumentaçáo no período mais recente pode ser apresentado, de forma sintética, como se segue.

O autor propóe, enfaticamente, que o investimento em educação deve ser convertido no eixo primordial do desenvolvimento. Como o automóvel foi tomado como eixo dos modelos econômicos vigentes até agora, trazendo consequências danosas, sua substituição pela educação propiciaria um desenvolvimento benéfico para toda a sociedade em todos os campos econômico-sociais. Ou seja, haveria maior distribuição da renda, estímulos para a igualdade social, além de trazer "o antídoto aos efeitos negativos" causados pelo modelo pautado no automóvel, desencadeando, assim, o "táo desejado círculo virtuoso": aumento dos empregos e dos salários e, dessa forma, "inclusão social", incremento do consumo, que ativaria o setor produtivo (indústria e agricultura) e o comércio, criando assim mais empregos, melhora na competitividade das empresas, crescimento exponencial da "arrecadação de impostos com os quais o Estado poderá resolver os problemas de infraestrutura [...] e arcar com os programas sociais [...] nesse amplo processo de desenvolvimento geral do país" (SAVIANI, 2010a, p. 246).

Para ele, o maior obstáculo para a realização dessa proposição, que acarretaria benefícios a todos, é a falta de vontade política dos empresários e políticos que, em seu discurso, admitem o papel privilegiado que caberia à educação para o desenvolvimento, mas não o colocam em prática. Por isso, frequentemente, o autor denunciou essa incoerência entre o discurso e a prática, manifestou-se impaciente com ela e, por vezes, adotou uma posiçáo bastante irônica, como forma de denunciá-la. Contudo, é preciso deixar claro que sua ironia foi dirigida àquela incoerência e, portanto, à falta de vontade política, e não à sua proposta de transformar a educação na principal mola propulsora do desenvolvimento com todas suas benéficas consequências. Em sua proposição não há nenhuma ironia. Pelo contrário; deixa explícita sua crença na proposta, o que justifica a defesa incondicional que faz dela e, ao mesmo tempo, sua irritação com a falta de vontade política para colocá-la em prática.

Saviani também argumenta que, além dos benefícios já apresentados, a proposta de converter a educação no eixo principal do desenvolvimento é concernente com a luta socialista, na medida em que sua realização implicaria um processo de socialização dos meios de produçáo, já que, para ele, o conhecimento é um meio de produção, "solapando a própria base do sistema capitalista". Paralelamente, o autor reivindica a necessidade de "publicização do Estado".

Cremos que seja necessário levantar alguns questionamentos ao entendimento de Saviani acerca da relaçáo entre desenvolvimento e educação, bem como, principalmente, à sua proposta. 
Primeiramente parece-nos necessário sinalizar que o desenvolvimento econômico é sempre de uma forma histórico-concreta. No capitalismo ele é, necessariamente, um desenvolvimento econômico capitalista, no qual imperam as leis universais do movimento contraditório do capital. Os chamados problemas econômico-sociais, como o desemprego, a pobreza, a miséria, a fome, a "concentração de renda", o ataque desmesurado ao meio ambiente, a tendência de queda da taxa de lucro, a recessáo, a depressão e as crises econômicas, etc. não são outra coisa senão os efeitos visíveis causados pela lógica de produção e acumulação de capital, ou seja, pelo próprio desenvolvimento econômico capitalista. Um investimento privilegiado em educação, transformando-a em eixo central do desenvolvimento econômico, poderia alterar as leis que regem o movimento do capital e, dessa maneira, produzir efeitos benéficos para o conjunto da sociedade, como reivindica Saviani? Considerando a base material capitalista, seria possível supor que a efetivação dessa proposta poderia criar "o tão desejado círculo virtuoso do desenvolvimento" e, portanto, as condiçóes para superação dos problemas sociais em geral, como a desigualdade, os problemas ambientais e infraestruturais, como advoga o autor?

Se o encaminhamento para a superação dos problemas sociais é tão cristalino e relativamente simples, por que Marx empenhou parte considerável de sua vida, com custos altíssimos, para estudar e compreender o capital? Por que ele e outros marxistas se dedicaram a elaborar estratégias revolucionárias com base na análise da realidade capitalista, e a organizar a classe trabalhadora para que esta buscasse implementá-las? Não teria a proposta defendida por Saviani um desenho mais liberal que marxista? Ela não incorporaria traços da "teoria do capital humano"? Por que suas principais críticas foram dirigidas ao "neoliberalismo" e não ao capitalismo? Não estaria reivindicando um estado de tipo keynesiano? Sua estratégia de ação política não teria um caráter reformista, de cunho socialdemocrata? Sua compreensão de que "falta vontade política" não estaria marcada por um desvio idealista?

O entendimento de tal formulação no interior de uma proposta que se situa no campo da luta socialista requer um esforço de compreensão para captar seu projeto político-estratégico. Ao reiterar a estratégia da educação como centro do desenvolvimento, esta foi apresentada como uma imposição dos novos tempos. Saviani (2010c, p. 260) considera que se apoiou na análise dialética feita por Marx, identificando a unidade entre produçáo, distribuiçáo, troca e consumo no processo de produção social enquanto totalidade orgânica, para concluir que, à luz dessa compreensão, "cabe entender a educação como um bem de produção, e não apenas um bem de consumo". Sem aprofundar essa afirmação, o autor preconizou que a dicotomia entre educação e economia não faria mais sentido devido à reestruturaçáo produtiva, que "guindou a educação a um lugar central no processo econômico".

Tomando-a como eixo do desenvolvimento, Saviani (2010c, p. 255) indicou que, lutando pela educação, pelas políticas públicas, o Estado seria utilizado 
"como instrumento de neutralização do processo de apropriação privada dos bens socialmente produzidos", apontando assim para a "socialização da economia" e, no limite, para a própria "superação do capitalismo". É no interior dessa lógica que se torna possível entender sua proposta. Em que medida ela náo significa a troca de uma estratégia revolucionária e, portanto, socialista por uma estratégia de desenvolvimento capitalista? Seria possível "socializar a economia" por meio do desenvolvimento econômico capitalista, com a intervenção do estado burguês, sem uma revolução que socialize os meios de produção?

Em segundo lugar aparece a questão do Estado. A proposta, reivindicada por Saviani, de publicização do Estado não estaria em desacordo com a tradição teórico-política do marxismo? Não sacrificaria o caráter de classe do Estado, tal como caracterizado pelos autores de linhagem marxista? Seu fundamento origina-se da leitura que faz da obra gramsciana, que concebe uma necessária alteração no conceito de Estado e nas formas de luta. A seu ver, o “conceito de Estado está 'alargando'-se”, bem como o de partido, exigindo atuação tanto na sociedade política quanto na sociedade civil. Como o partido ideológico visaria à hegemonia no seio da sociedade por intermédio da sociedade civil, isso o levou à conclusão de que "a educação é chamada a desempenhar um papel de transcendental importância”, já que a hegemonia "implica sempre uma relação pedagógica" (SAVIANI, 2011, p. 201).

Seria necessário debater a própria concepção de hegemonia e de sociedade civil, mas nos limites deste artigo nos atemos a questionar sua concepção de Estado. Somente para citar um exemplo, sua proposta não entraria em choque com a profunda análise acerca do Estado que faz Lênin (1987) em $O$ Estado e a revolução, baseado na contribuição de Marx e Engels, em que critica fortemente a ideia de um "Estado popular"? Se se pode "publicizar o Estado", ou seja, ir tornando-o "público", por que Marx, Engels, Lenin, e o próprio Gramsci, para mencionar apenas os principais expoentes marxistas, insistiram tanto na necessidade de destruição do Estado capitalista, por meio de uma revoluçáo violenta?

$\mathrm{Na}$ leitura que fazemos de Gramsci, o Estado socialista não é uma continuação do Estado burguês, e, portanto, não é possível disputá-lo. Para ele (GRAMSCI, 1976, p. 81), "É preciso que o próprio poder passe para os trabalhadores, mas estes nunca o poderão ter até que se iludam de podê-lo conquistar e exercer através dos órgãos do Estado burguês". Se fosse possível ir "publicizando o Estado" de tal maneira a satisfazer os interesses do "povo", por que a necessidade de sua destruição, quer dizer, da revolução? Por que a necessidade de organizar a classe trabalhadora para que ela possa elaborar e implementar uma estratégia revolucionária? A compreensão de Estado de Saviani não teria marcas de uma concepção liberal?

Em terceiro lugar, é necessário apreciar um argumento bastante caro para Saviani, o do conhecimento como força produtiva, como meio de produ- 
ção. Em seus textos, ele apresenta o conhecimento ora como força produtiva, ora como meio de produção, tratando-os de maneira indiferenciada. Não estaria confundindo força produtiva com meio de produção? Será que o suposto de que o conhecimento é meio de produção encontra sustentação na elaboração teórica marxiana? No capítulo V de $O$ capital, por exemplo, Marx (1983) se dedica a explicar o processo simples de trabalho formado pela força de trabalho e pelos meios de produção, e define esses últimos como a composição de meios de trabalho e objetos de trabalho, cuja compreensão está esmiuçada em algumas páginas. Será que o conhecimento poderia ser considerado um meio de trabalho ou um objeto de trabalho e, dessa forma, um meio de produçáo? Parece que não. Contudo, pode-se argumentar que não haveria meio de produção sem que houvesse conhecimento, $o$ que nos parece uma verdade deveras óbvia, e que, por isso, um meio de produção seria um conhecimento objetivado.

Essas assertivas carregam em si alguns problemas. A produção de valores de uso que são resultado do trabalho humano, sejam eles meios de produção (por exemplo, uma máquina) ou meios de subsistência (por exemplo, uma camisa), pressupóe o conhecimento. Mas isso implica que são a mesma coisa, que se identificam? O conhecimento é a mesma coisa que uma máquina ou uma camisa? Em seu livro Escola e democracia, Saviani (2003, p. 81) se deparou com uma questão similar, derivada da "afirmação de que a educação é sempre um ato político". Embora esteja de acordo com a assertiva, ele (Saviani, 2003, p. 82) indaga: "educação e política se equivalem, se identificam? Se são diferentes, em que consiste a diferença?". Ele mesmo responde dizendo que entende "que educação e política, embora inseparáveis, não são idênticas. Trata-se de práticas distintas, dotadas cada uma de especificidade própria”. O autor não faz essa discussão por preciosismo. Ele teve necessidade de demarcar a diferença e as especificidades de cada uma dessas práticas justamente para poder oferecer uma compreensão da relação entre elas, já que se elas fossem idênticas não haveria relação entre elas, porque não há relação entre uma coisa e a mesma coisa. Essa argumentação feita por Saviani não valeria para compreender a relação entre conhecimento e meio de produção? Parece que sim.

Em nossa compreensão, o conhecimento é condição sine qua non para a fabricação de qualquer meio de produção, mas não se identifica com ele, não é a mesma coisa. Isso vale também para o argumento segundo o qual um meio de produção seria um conhecimento objetivado. Aqui cabe um esclarecimento adicional. Parece-nos que seria mais adequado o entendimento de que um meio de produção é trabalho objetivado e não conhecimento objetivado. Como valores de uso, os meios de produção, como também os meios de subsistência, são trabalho objetivado, ou mais precisamente, resultado de uma enormidade de trabalhos concretos realizados em diversos processos de trabalho específicos e articulados entre si numa cadeia produtiva, desde a primeira intervenção para coletar a matéria natural até a finalização do produto. Uma máquina, por exemplo, é resultado de 
uma infinidade de trabalhos concretos: dos trabalhadores que extraíram o minério, daqueles que o transportaram, dos que o transformaram em aço, etc., e também dos trabalhadores que produziram o conhecimento — os pesquisadores —, bem como daqueles que o transmitiram — os professores. Por isso, a rigor, a máquina náo seria conhecimento objetivado, mas sim, no que tange à questáo restrita aqui discutida, trabalho de produção e transmissão do conhecimento objetivado, ou, mais precisamente, trabalho objetivado de produção e transmissáo do conhecimento. Claro que ela é síntese de trabalho objetivado de uma infinidade de trabalhos concretos, mas estamos enfatizando os trabalhos concretos concernentes ao conhecimento porque é o foco do debate neste texto. Como consequência, a máquina, como meio de produção, bem como a camisa, como meio de subsistência, são trabalho objetivado, são máquina e camisa; já não são mais trabalho e muito menos conhecimento, mas sim meio de produção e meio de subsistência, respectivamente. Portanto, se é verdade que o conhecimento é condição necessária para a existência de um meio de produção e mesmo admitindo que esse seja conhecimento objetivado - pensamos que, a rigor, é trabalho objetivado — , isso não serviria para sustentar o argumento de Saviani de que conhecimento seja meio de produção, de que ambos se identificam.

$\mathrm{O}$ autor foi explícito ao vincular a educação escolar com a luta socialista, recorrendo a essa tese do "saber como meio de produção". Questionado sobre o sentido de sua proposta, argumentou que "por esse caminho estaremos solapando a própria base do sistema capitalista, uma vez que, socializando o conhecimento, que é uma força produtiva, um meio de produção, estaremos contrariando o princípio da apropriaçáo privada dos meios de produção" (SAVIANI, 2011, p. 199, grifos nossos). Aí residiria o motivo pelo qual "os grupos dominantes relutam em tirar as consequências práticas de seu próprio discurso”. Esse parece ser o fundamento de sua defesa da educação como determinante para o desenvolvimento da produção e da economia brasileiras, além de significar um instrumento estratégico na luta pela superação do capitalismo e construção do socialismo.

Tudo isso, portanto, implica alguns questionamentos. Se o conhecimento não é meio de produção, sua socialização, por meio da escola, não "contraria o princípio da apropriação privada dos meios de produção" e, portanto, não "solapa a própria base do sistema capitalista", conforme desejaria Saviani. Dessa forma, não ficaria rompida a relação entre sua proposta de transformar a educação no eixo principal do desenvolvimento econômico e a luta socialista, já que essa, para ele, deita suas raízes no suposto do conhecimento como meio de produção? Se sua proposição não tem mais vínculo com a luta socialista, que, para ele, ocorreria por meio da socialização do conhecimento pela escola, que objetivos reais conseguiria alcançar? Se os políticos e empresários se convencessem da excelência da proposta apresentada por Saviani e dotados de "vontade política" conseguissem ir para além do discurso, tirando-a do papel e, de verdade, a colocassem em prática, o que aconteceria? 
Para Saviani, a resposta é clara: um grande incremento, uma aceleração do desenvolvimento econômico capitalista. Que efeitos isso produziria? Um solapamento das bases de sustentação do sistema capitalista, pela socialização do conhecimento, vale dizer, de meios de produção? Parece que não. Aumento de emprego, "distribuição de renda", "inclusão social", diminuição da violência, enfim, resoluçâo dos problemas econômico-sociais, ambientais, etc., como o autor advoga? Será? Quais são os resultados de um desenvolvimento econômico capitalista, qualquer que seja seu principal motor, o "automóvel" ou a "educação"? A começar pelo próprio Marx, todos os principais pensadores-militantes marxistas vêm estudando profundamente, tanto estrutural como conjunturalmente, o modo capitalista de produção e parece-nos que suas conclusôes apontam numa direção diametralmente oposta àquela desejada por Saviani. Sendo assim, que sentido político teria sua proposta? Qual seria o significado político para a classe trabalhadora de uma estratégia que tem como seu horizonte o desenvolvimento econômico capitalista tendo como eixo a educação? Para qual terreno político conduziria a classe trabalhadora e a luta de classes?

As considerações e questionamentos feitos anteriormente adquirem uma maior relevância na medida em que, como se sabe, Saviani é o principal fundador e o maior expoente da chamada pedagogia histórico-crítica, proposta que se inscreve no âmbito do marxismo. Diante disso destacamos a importância desse debate.

Essas são algumas das questóes com as quais nos deparamos para pensar a luta de classes nesse momento difícil para a classe trabalhadora mundial. A clareza na definição de um projeto político é fundamental para os rumos que a história pode tomar, embora não haja garantias de sucesso. Não se trata aqui de negar o papel que desempenham a educação e a escola pública na sociedade na qual vivemos, o capitalismo. Muito pelo contrário. Elas têm uma importância crucial, mas, do ponto de vista dos interesses históricos da classe trabalhadora, ambas têm de ser pensadas como componentes de um projeto estratégico que tenha como finalidade a superação do sistema capitalista e a construçáo de uma ordem social em que o gênero humano possa desenvolver-se em sua plenitude. Acreditamos que as respostas aos questionamentos feitos ao longo deste artigo poderão oferecer algumas contribuiçóes para a realização dessa imprescindível tarefa histórica.

\section{Referências}

GRAMSCI, A. Socialista ou comunista? Escritos politicos. Vol. 2. Lisboa: Seara Nova, 1976.

LENIN, V.I. O Estado e a revolução. São Paulo: Hucitec, 1987.

MARX, K. O Capital: crítica da economia política. São Paulo: Abril Cultural, 1983.

SAVIANI, D. Desafios de políticas educacionais no Brasil: política social e publicização da educação. Psicologia: Ciência e Profissáo, v. 9, n. 3, p. 5-7, 1989. 
. O trabalho como princípio educativo frente às novas tecnologias. In: FERRETTI, C.J. et al. (Orgs.). Novas tecnologias, trabalho e educação: um debate multidisciplinar. Petrópolis: Vozes, 1994, p. 151-166.

Da nova $L D B$ ao novo Plano Nacional de Educação: por uma outra política educacional. 4a. ed. rev. Campinas: Autores associados, 2002. (Coleçâo educação contemporânea)

. Escola e democracia: teorias da educaçáo, curvatura da vara, onze teses sobre a educação política. 36a. ed. rev. Campinas: Autores Associados, 2003. (Coleção polêmicas do nosso tempo; vol. 5)

. O legado educacional do "longo século XX" brasileiro. In: et al. $O$ legado educacional do século XX no Brasil. Campinas: Autores Associados, 2004, p. 9-57. (Coleção educação contemporânea)

. As concepçôes pedagógicas na história da educação brasileira. In: LOMBARDI, J. C. et al. (Orgs.). Navegando pela história da educação brasileira. Campinas: Gráfica FE: HISTEDBR, 2006, CD-ROM, p. 1-38. Disponível em: <http://www.histedbr.fae. unicamp.br/navegando/artigos_frames/artigo_036.html>. Acesso em: janeiro de 2012.

Da nova $L D B$ ao FUNDEB: por uma outra política educacional. 3a. ed. Campinas: Autores associados, 2008a. (Coleção educação contemporânea)

. Entrevista: motor do desenvolvimento. Educação, São Paulo, v. 12, p. 6-10, out., 2008b.

Interlocuçóes pedagógicas: conversa com Paulo Freire e Adriano Nogueira e 30 entrevistas sobre educação. Campinas: Autores Associados, 2010a. (Coleção memória da educaçấo)

O Estado e a promiscuidade entre o público e o privado na história da educaçấo brasileira. In: (Org.). Estado e politicas educacionais na história da educação brasileira. Vitória: EDUFES, 2010b, p. 15-44. (Coleção horizontes da pesquisa em história da educação no Brasil; v. 2)

A educaçáo no centro do desenvolvimento econômico. In: BARROSO, A.; RENILDO, S. (Orgs.). Desenvolvimento: ideias para um projeto nacional. Saao Paulo: Anita Garibaldi; Fundação Maurício Grabois, 2010c, p. 247-264. da educaçáo)

Educação em diálogo. Campinas: Autores associados, 2011. (Coleçấo memória

Recebido em 05 de maio de 2015.

Aprovado em 27 de abril de 2016. 